\title{
THE MAF FERTILISER ADVISORY SERVICE
}

\section{I.S. CORNFORTH ${ }^{1}$ and A.G. SINCLAIR2 \\ Ministry of Agriculture and Fisheries \\ Ruakura ${ }^{1}$ and Invermay ${ }^{2}$}

\section{Abstract}

The MAF Fertiliser Advisory Service provides fertiliser and lime recommendations for pastures, lucerne and cereal crops. It does this by combining farm details with an understanding of the behaviour of nutrients in soils, plants and animals derived from many years of soil fertility research. Recommendations are for individual farms or blocks of land. Balance models are used in which fertiliser requirements are calculated to replace nutrients lost from cycling pools via animals and within the soil. Soil tests assess the influence of previously applied fertilisers and via animals and within the soil. Soil tests assess the influence of previously applied fertilisers and
are used to modify recommendations. A technical report showing fertiliser options is prepared for advisers while short and long term recommendations are given in a more basic report addressed to the farmer.

Keywords: Fertiliser recommendations, soil testing, pastures, cereals, lucerne.

\section{INTRODUCTION}

The MAF Fertiliser Advisory Service provides fertiliser and lime recommendations for pastures, lucerne and cereal crops. It does this by combining farm details and soil tests with an understanding of the behaviour of nutrients in soils, plants and animals obtained from many years of soil fertility research.

The sewice has been designed to assist professional advisers and consultants to provide farmers with a personalised service in which fertiliser and lime recommendations can be integrated with overall management advice. As such it is only available through MAF's Advisory Services Division Farm Advisory Officers or through farm management consultants registered to use MAF's soil testing senices. The final responsibility for fertiliser advice remains with these advisers since we acknowledge that the fertiliser requirements for a particular farm are unique and that not all the factors which influence requirements can be incorporated into generalised models or calculations.

\section{NUTRIENT REQUIREMENTS}

We know that most New Zealand soils needed fertilisers containing phosphorus and sulphur when productive pastures were developed from the original vegetation. We also know that these fertilisers must continue to be applied, although generally at a reduced rate, if developed land is to continue to produce well. We know that continued production can lead to deficiencies of other nutrients, such as potassium and magnesium and that in some circumstances these must also be applied as maintenance fertilisers.

It was originally thought that the continuing need for phosphate fertilisers was because our soils "locked up" most of the added phosphate in forms that could not be used by plants. While this process certainly does occur, it is less important than was once assumed. It is now clear that fixation is not the only way in which phosphates are lost from grazed pastures. Losses via animals, in produce or excreta, can be just as important.

It is easy to visualise what is happening if we consider a cycle in which phosphate is taken up from the soil by plants (Fig. 1). Plants which are not eaten by animals die, decay and return the phosphorus to the soil. Most of the phosphorus in the plants eaten by animals is also excreted back to the soil where it is available for re-use, thus completing the cycle. Unfortunately some phosphorus is excreted in camp sites or in yards and races and is therefore wasted. All animal products sold from the farm also contain phosphorus. It is these animal losses, together with the phosphorus which is 


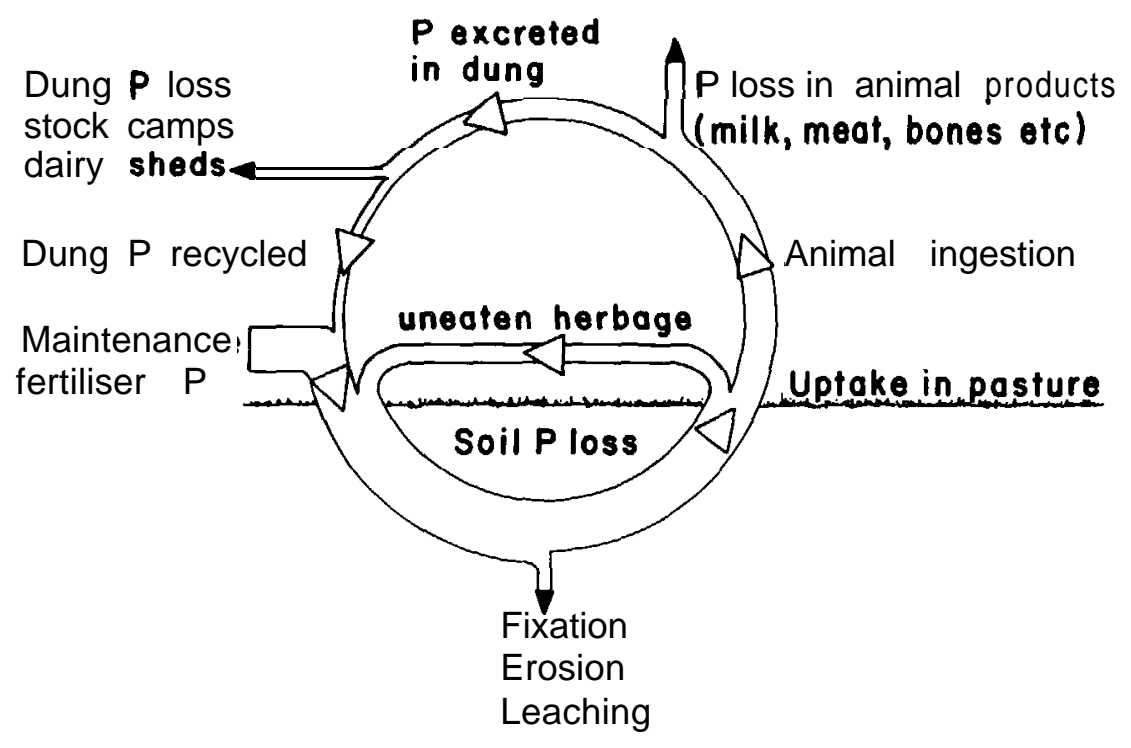

FIGURE 1: The Phosphate Cycle in Grazed Pastures.

made unavailable in the soil, which must be replaced or production will decline.

Similar losses occur with all the essential plant and animal nutrients, although the way in which they occur may vary. For example sulphur and potassium are easily washed out of some soils by percolating rain water. Some soils can replace a proportion of the lost potassium and magnesium by release from slowly available reserves in the clay particles. Soil suphur can be replenished in areas where prevailing winds blow in sulphur-containing rain from the sea. Unfortunately there are few natural sources of phosphorus and losses must be replaced with fertilisers.

In general, nutrient losses increase with farm production. Animal losses depend on the type of stock, as well as their numbers. Losses in excreta depend on land slope through its influence on grazing habits. Losses in the soil depend on the type of soil and on climate, especially rainfall. If we accept that maintenance fertilisers are applied to replace nutrient losses and that losses depend on production, stock type, soil and climate, then it is obvious that each farm will have its own unique fertiliser requirements.

This is the approach taken by MAF's fertiliser advisory scheme. Forty or more years of fertiliser research have given us a reasonably good understanding of how the main nutrients behave in grazed pastures. We have used the ideas of nutrient cycling and balance to calculate the maintenance requirements of individual farms or blocks of land. Details of farm production and operation are used to calculate the amount of feed required. Estimates of nutrient losses indicate maintenance fertiliser requirements. Finally soil tests are used to adjust maintenance requirements to allow for the current fertility of the soil.

\section{SOIL TESTING}

Soil tests are used to assess the original fertility of unimproved soils and to measure the effects of fertiliser history and farm practice on the fertility of developed soils. The MAF fertiliser advisory scheme relies mainly on soil test results for calculating fertiliser requirements for land development, although anticipated production is also con- 


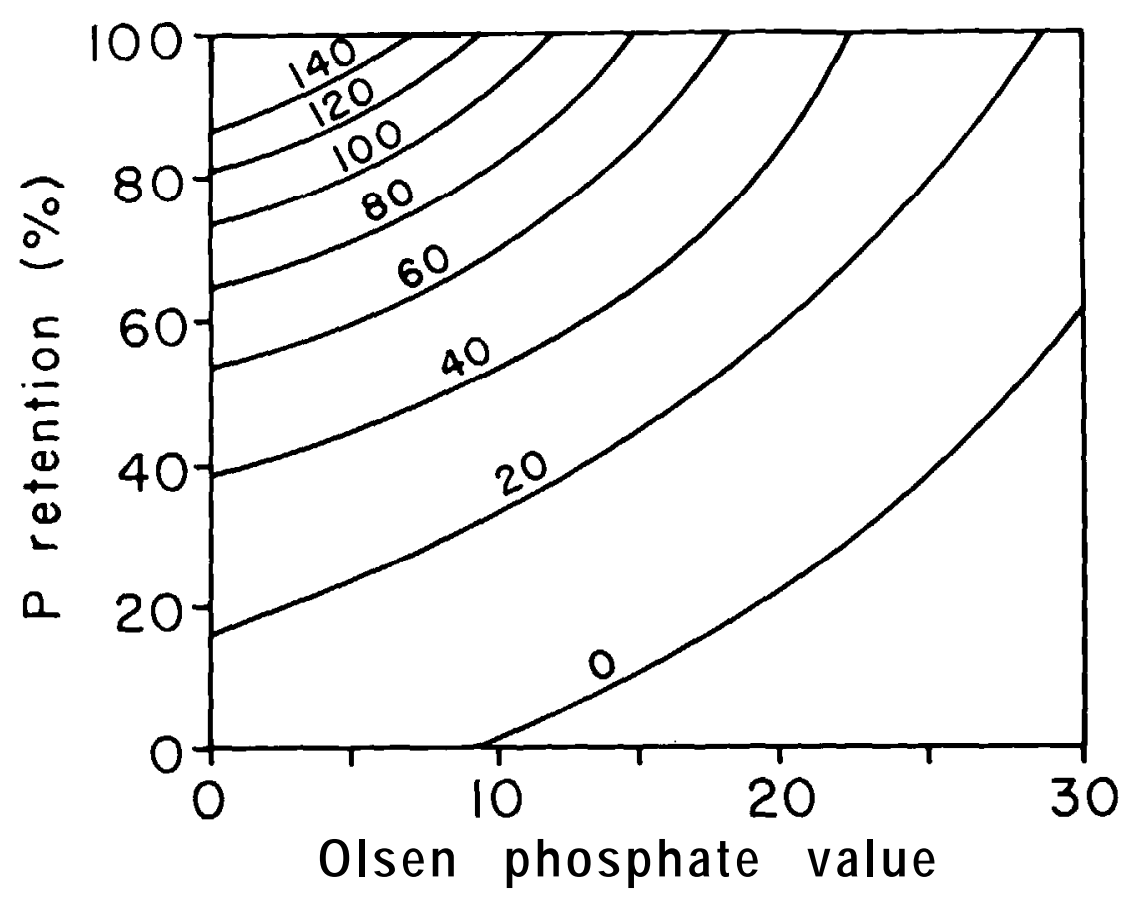

FIGURE 2: The Phosphorus Requirements for Pasture Establishment. The Number on Each Curve Gives kg/P ha Required to Establish Pasture on a Soil Corresponding to Any Point on the Curve.

sidered. Fig. 2 shows the relationships used to estimate phosphorus requirements from Olsen phosphate and phosphate retention values.

Tests are used in a less direct way for calculating fertiliser requirements for developed land. For these, the nutrients required to balance losses occurring at the desired level of production are first calculated. Application of these calculated amounts of nutrients should maintain a steady level of fertility from year to year. However, soil tests may show that some nutrients are already present in more than adequate amounts, possibly as a result of excessive fertiliser use; in such cases fertiliser rates less than the calculated maintenance are recommended in the short term. Conversely, if soil tests show that soil fertility has been seriously depleted through insufficient fertiliser use then more than the calculated maintenance rate is recommended in order to restore fertility as well as compensate for losses. Thus in developed pasture soil tests are used to modify the calculated maintenance rates of fertiliser. Optimum soil test values are different for different soil groups, and also depend on the desired relative yield of pasture DM (i.e. the quantity which needs to be grown relative to the potential maximum). Fig. 3 shows the Olsen $\mathrm{P}$ soil test values at which unadjusted maintenance rates of $\mathrm{P}$ should be applied. (Optimum relative yields are generally $90-95 \%$ for dairy and intensive sheep pastures, and $80-90 \%$ for hill country pastures.)

\section{Lime Requirements}

The amount of lime required for pasture establishment is calculated from the initial $\mathrm{pH}$ of the soil and target $\mathrm{pH}$ values known to be required by the pasture species sown. For developed land the yield responses to different application rates of lime are 


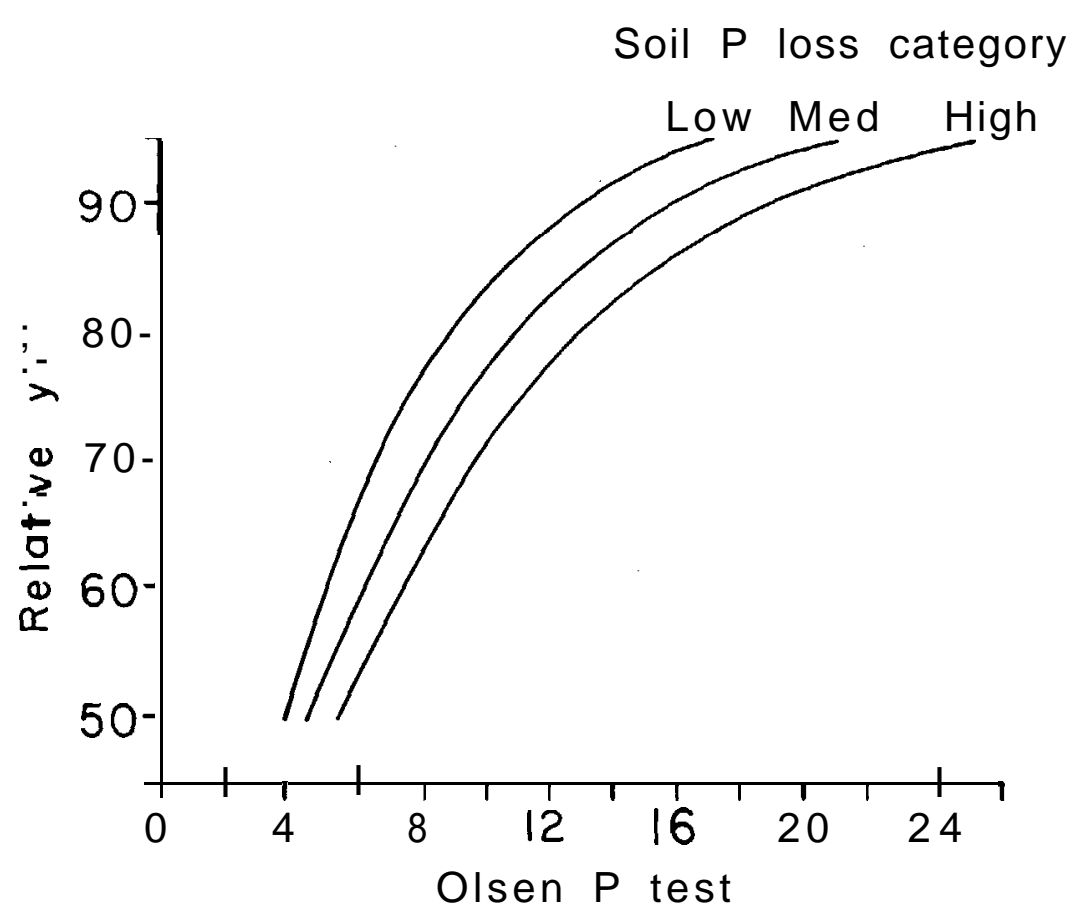

FIGURE 3: Olsen P Soil Test Values at Which Unadjusted Maintenance P Fertiliser Rates Should Be Used.

estimated from the current $\mathrm{pH}$ of the soil using the relationships shown in Fig. 4. The extra stock which could be carried and the likely duration of the responses are also estimated, providing advisers with information which they can use along with local costs of lime, transport and application to calculate the most economical rate of lime to apply on each individual paddock.

\section{FERTILISER RECOMMENDATIONS}

The computers used to calculate recommendations produce two reports for each block of land tested. One report is fairly technical and is meant for the adviser who is assisting the farmer. It contains recommendations for each paddock sampled, to allow the adviser to decide whether a uniform fertiliser application for the block is appropriate or whether some paddocks need individual treatment. Additional information is provided which shows the nutrient requirements associated with stocking rates which are either slightly more or less than the rates originally proposed. The effects of grazing management on nutrient requirements are also shown. This is to help the adviser to fit the fertiliser recommendation into his overall management advice.

The second report produced by the computer is addressed to the farmer. It contains his soil test results, and the amount of nutrients required both in the immediate future and for long term maintenance. These are given on a block basis, not for individual paddocks. Finally fertilisers are recommended which provide the short and long term nutrients requirements in the cheapest (ex-works) form available locally. 


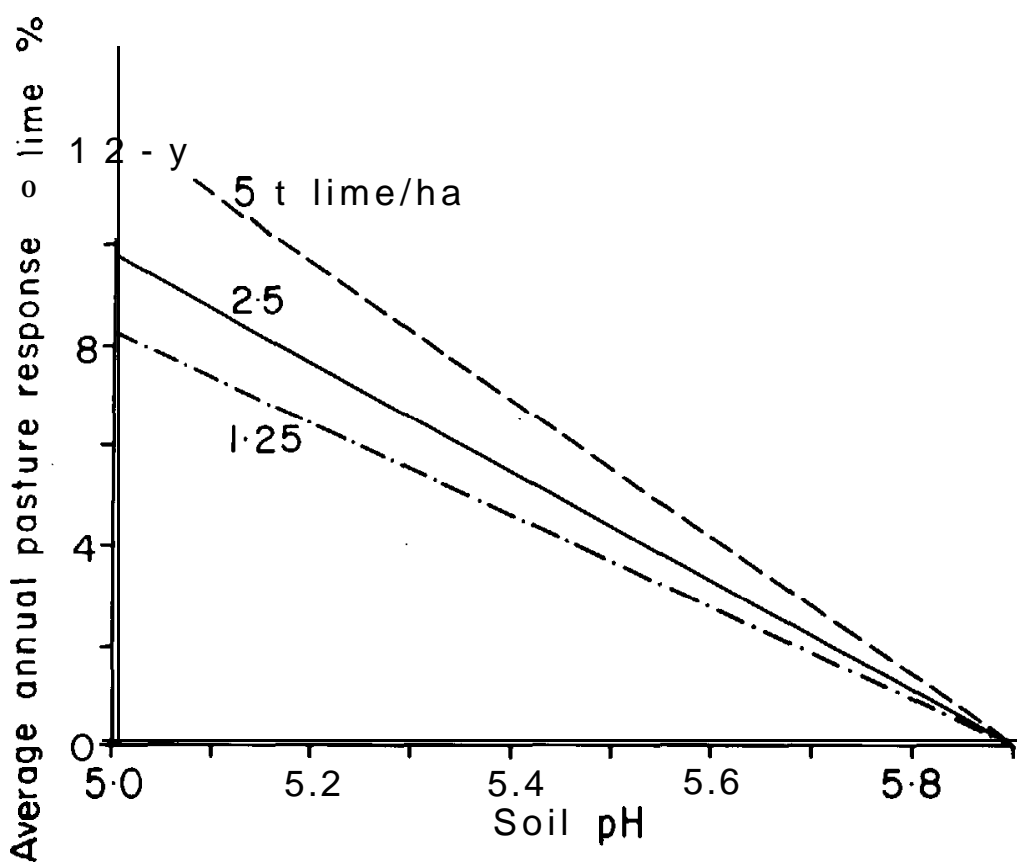

FIGURE 4: Relationships Between Soil pH and Average Annual Pasture Response to Lime Applied at 3 Rates (Edmeades et al. 1985).

Both the technical report and the farmer's report are sent to the adviser who must decide whether or not to amend the recommendations before he passes them onto the farmer. The adviser has been given responsibility for the recommendations because he may be aware of local conditions which make the computer calculations inappropriate for a particular farm.

\section{The Fertiliser Bulletin}

All the basic models and the data required for making fertiliser recommendations have been published in a bulletin "Fertiliser recommendations for pastures and crops in New Zealand" (Cornforth and Sinclair 1984). While recommendations can be derived from data in this bulletin, in practice computers used for the MAF soil testing services are used to make the necessary calculations. Guidelines for operating the computerised service are available for professional advisers (Metherell and Morrison 1984), while a MAF AgLink (Metherell and Parker 1984) describes it for farmers.

\section{Monitoring F ertility}

The effects of applying the recommendations from the fertiliser advisory scheme on soil fertility are being monitored on 200 commercial farms and a number of research areas throughout the country. The scheme will be reviewed at regular intervals and changes indicated by the monitoring programme and the results of new research will be added. Farmers can monitor the fertility of their own land by having soils retested every 2-4 years. If fertiliser rates greater or less than the calculated maintenance rates are applied, changes in fertility should be checked more frequently. 


\section{FUTURE DEVELOPMENT}

Current work aims at refining the models used in calculating requirements. In addition considerable efforts are being made to predict changes in soil fertility and productivity which occur when fertiliser regimes are changed. This is essential information if we are to be able to apply more rigorous economic criteria to decisions on fertiliser use in future.

Fertiliser costs have increased considerably over the last ten years and there is no reason to believe that the increases will not continue. But fertilisers are still a good investment. The best way to improve the efficiency of fertiliser use and to ensure the maximum return on money spent on fertilisers is to use just the correct amount to achieve production targets for any set of circumstances. It is the aim of MAF's fertiliser advisory service to make that prediction for individual farmers.

\section{References}

Cornforth, I.S.; Sinclair A.G. 1984. Fertiliser and lime recommendations for pastures and crops in New Zealand. Second Revised Edition, MAF, Wellington.

Edmeades, D.C.: Pringle R.M.; Mansell, G.R.; Shannon, P.W.; Ritchie, J.: Stewart, K.M. 1985. N.Z. J. exp. Agric. 13: $47-58$

Metherell, A.K.; Morrison, J.D. 1984. Guidelines for the computerised fertilier advisory service (CFAS) MAF, Wellington.

Metherell, A.K.; Parker, B.W. 1984. Soils: Testing for fertiliser advice. AgLink FPP825, MAF,

Wellington. 